\title{
ANALISIS KAPASITAS SALURAN DRAINASE MENGGUNAKAN PROGRAM SWMM 5.1 DI PERUMAHAN TASMANIA BOGOR, JAWA BARAT
}

\section{(Drainage Channel Capacity Evaluation Using SWMM 5.1 in Tasmania Residence Bogor, West Java)}

\author{
Luthfi Kartiko ${ }^{1}$ dan Roh Santoso Budi Waspodo ${ }^{1^{*}}$ \\ ${ }^{1}$ Departemen Teknik Sipil dan Lingkungan, Fakultas Teknologi Pertanian, Institut Pertanian Bogor. \\ Jl. Raya Dramaga, Kampus IPB Dramaga, PO BOX 220, Bogor, Jawa Barat Indonesia \\ Penulis korespondensi: Luthfi Kartiko. Email: kartiko.luthfi@gmail.com
}

Diterima: 19 Oktober 2018

Disetujui: 30 November 2018

\begin{abstract}
The intensity and duration of rainfall will affect the amount of runoff. A proper drainage design is needed so that runoff from maximum rainfall would not cause a problem such as excess water or flood. The purpose of this research were to analyze the runoff volume in Tasmania Regency, Bogor and get drainage network design in accordance with the runoff that occured. Analysis was carried out using SWMM 5.1 software with designed rainfall was calculated using the Log-Person III method of $147.2 \mathrm{~mm}$. Peak discharge runoff from simulation results were $0.01-0.08 \mathrm{m3} / \mathrm{s}$. Based on the simulation there were 20 channels overflowed during maximum runoff and 6 channels were high potentially overflowed so that repairs were also needed. The factors that influenced were the amount of runoff, channels capacity were lower than runoff volume, and the low infiltration value of subcatchment so that only a little water could be infiltrated and the rest of rainfall became runoff..

Keywords: drainage channel, rainfall, runoff, SWMM 5.1
\end{abstract}

\section{PENDAHULUAN}

Indonesia adalah negara berkembang yang memiliki jumlah penduduk sebanyak 237.641.326 jiwa dengan laju pertumbuhan penduduk sebesar $1,49 \%$ setiap tahunnya berdasarkan data dari Badan Pusat Statistika pada sensus penduduk tahun 2010. Kota Bogor sendiri memiliki jumlah penduduk sebesar 1.030.720 jiwa di tahun 2014 (BPS 2017). Dengan terus bertambahnya jumlah penduduk, kebutuhan untuk tempat tinggal juga terus bertambah. Dampak negatif dari pembangunan perkotaan antara lain berupa semakin berkurangnya daerah terbuka yang berfungsi sebagai daerah peresapan air, timbulnya pemukimanpemukiman ilegal di sepanjang sungai dan permukaan lahan yang menurun karena pengambilan air tanah yang melebihi besarnya imbuhan air tanah (Sudarmanto 2010). Menurut Kodoatie (2005), penyebab banjir karena tindakan manusia beberapa diantaranya adalah perubahan tata guna lahan (land-use), pembuangan sampah, kawasan kumuh di sepanjang sungai/drainase, dan perencanaan sistem pengendalian banjir yang tidak tepat. Permukaan tanah yang dahulu sebagai daerah resapan air telah beralih fungsi menjadi bangunan maupun jalan, sehingga menyebabkan bertambahnya kelebihan air yang ada di permukaan terutama saat musim penghujan. Dengan berkurangnya daerah resapan air, maka volume air limpasan yang tidak terserap oleh tanah akan semakin besar dan berpotensi menimbulkan genangan-genangan yang 
dapat mengakibatkan banjir disaat musim penghujan.

Pembangunan drainase yang baik pada daerah perumahan diperlukan untuk menyalurkan air limpasan sehingga mengurangi potensi timbulnya genangan-genangan yang dapat mengakibatkan banjir. Drainase adalah istilah untuk tindakan teknis penanganan air kelebihan yang disebabkan oleh hujan, rembesan, kelebihan air irigasi, maupun air bangunan rumah tangga, dengan cara mengalirkan, menguras, membuang, meresapkan, serta usaha-usaha lainnya, dengan tujuan akhir untuk mengembalikan ataupun meningkatkan fungsi kawasan (Ardian et al. 2016). Saluran drainase adalah bangunan air yang memiliki fungsi penting untuk menyalurkan kelebihan air yang ada di permukaan. Dengan adanya saluran drainase yang baik, kelebihan air dapat tersalurkan dan mengurangi potensi munculnya genangan maupun banjir disaat musim penghujan.

Perumahan Tasmania berlokasi di

Kota Bogor, Jawa Barat. Saat ini saluran drainase di perumahan tersebut tidak dapat menampung limpasan yang terjadi saat hujan dengan intensitas tinggi. Salah satu solusi untuk membantu mengevaluasi sistem drainase perkotaan adalah dengan menggunakan sebuah pemodelan runoff yakni software SWMM (Tamimi et al. 2016). Dengan adanya saluran drainase yang baik, kelebihan air yang ada di permukaan dapat dikendalikan sehingga dapat mencegah terjadinya genangangenangan air maupun banjir di wilayah tersebut. Metoda yang digunakan dalam pemodelan runoff ini adalah model EPA SWMM 5.1. SWMM dapat digunakan untuk memperkirakan kemampuan suatu saluran dalam menampung limpasan pada sebuah sistem drainase.

\section{METODOLOGI}

Evaluasi saluran drainase yang akan dianalisis adalah saluran drainase yang berada di Perumahan Tasmania, Bogor, Jawa Barat. Penelitian dilaksanakan pada bulan Maret hingga bulan Juli 2018. Peta Lokasi Penelitian dapat dilihat pada Gambar 1. Bahan yang digunakan pada penelitian ini terdiri dari data primer dan data sekunder. Data primer berupa dimensi saluran dan karakteristik saluran drainase. data sekunder berupa data curah hujan maksimum selama 10 tahun di daerah Kota Bogor, dan citra satelit Perumahan Tasmania. Data curah hujan tahunan daerah Kota Bogor didapatkan dari situs resmi pemerintah http://dataonline.bmkg.go.id, dan citra satelit Perumahan Tasmania didapatkan menggunakan software Google Earth yang diambil pada tanggal 1 Juli 2018. Alat yang digunakan yaitu kompas, theodolite, target rod, patok, laptop, alat tulis, kalkulator, dan software EPA SWMM 5.1.

Pengolahan data dimulai dengan menentukan nilai curah hujan rencana serta daerah pervious dan impervious menggunakan data sekunder yang telah didapatkan. Identifikasi daerah pervious dilakukan dengan melakukan validasi lapang di lapangan untuk melihat daerah yang dapat menyerap air melalui infiltrasi (pervious) dan daerah yang tidak dapat melewatkan air (impervious). Kemudian dapat dihitung persentase luas daerah pervious dan impervious untuk setiap subcatchment, sebagai input data dalam subcatchment. Curah hujan rencana adalah curah hujan terbesar yang mungkin terjadi disuatu daerah pada periode ulang tertentu yang dipakai sebagai dasar perhitungan perencanaan suatu bangunan (Krisnayanti et al. 2017). Analisis 


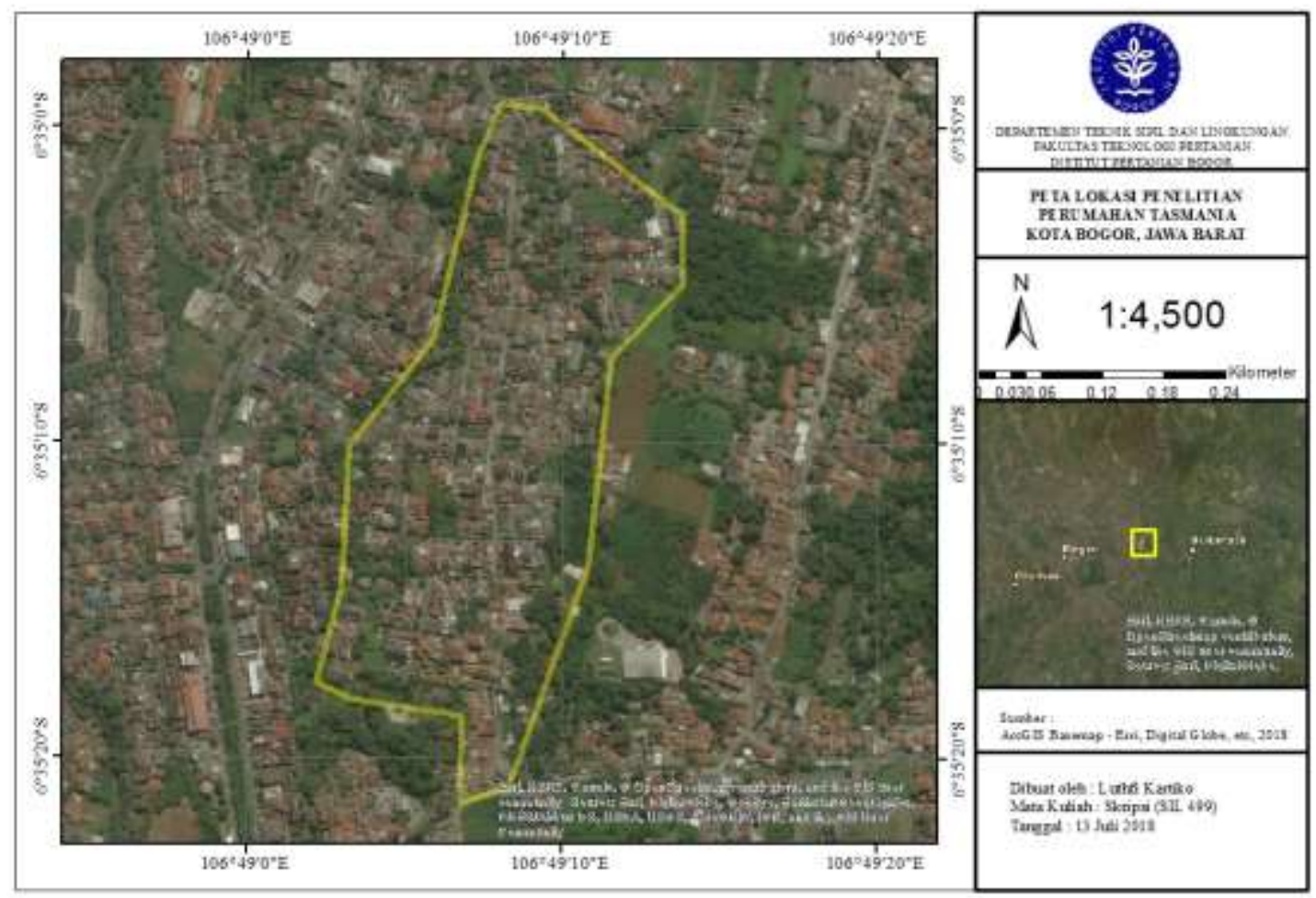

Gambar 1. Peta lokasi Penelitian

frekuensi untuk mendapatkan nilai curah hujan rencana dilakukan dengan menggunakan teori probability distribution, antara lain Distribusi Normal, Distribusi Log Normal, Distribusi Log Person III dan Distribusi Gumbel. Selanjutnya untuk penentuan jenis distribusi yang digunakan akan dilakukan uji kecocokan berdasarkan $\mathrm{Uj}$ i Chi Kuadrat. Bentuk distribusi chi kuadrat tergantung dari derajat bebas (Db) (Isfandari dan Reini 2014). Data yang diperoleh kemudian diolah menggunakan pemodelan EPA SWMM 5.1. Penelitian dilakukan dengan langkah-langkah seperti pada Gambar 2.

Metode perhitungan infiltrasi pada pervious area menggunakan metode Horton. Untuk nilai infiltrasi dari kondisi tanah memiliki dua nilai yaitu nilai infiltrasi maksimum (Tabel 1) dan nilai infiltrasi minimum (Tabel 2) (Rossman 2015). Sementara itu, untuk debit dari limpasan subcatchment dihitung dengan persamaan (1) dan (2) (Babbit 1969).

$V=\frac{1}{n} \cdot R^{\frac{2}{3}} \cdot S^{\frac{1}{2}}$

$Q=V \cdot A$

Keterangan :

$\mathrm{V}=$ kecepatan aliran $(\mathrm{m} /$ det $)$

$\mathrm{R}=$ jari-jari hidrolis $(\mathrm{m})$

$\mathrm{n}=$ koefisien Manning

$\mathrm{S}=$ kemiringan saluran

$\mathrm{A}=$ luas penampang saluran terbasahkan $\left(\mathrm{m}^{2}\right)$

$\mathrm{Q}=\operatorname{debit}\left(\mathrm{m}^{3} / \operatorname{det} \mathrm{ik}\right)$ 


\begin{tabular}{cllc}
\hline No. & \multicolumn{1}{c}{ Kondisi tanah } & Jenis tanah & $\begin{array}{c}\text { Infiltrasi maksimum } \\
(\mathrm{mm} / \mathrm{jam})\end{array}$ \\
\hline 1 & $\begin{array}{l}\text { Kering dengan sedikit } \\
\text { atau tidak ada } \\
\text { tumbuhan }\end{array}$ & Tanah berpasir & 5 \\
& & Tanah lempung & 3 \\
2 & $\begin{array}{l}\text { Kering dengan banyak } \\
\text { tumbuhan }\end{array}$ & Tanah liat & 1 \\
& & Tanah berpasir & 10 \\
& & Tanah liat & 6 \\
& Tanah lembab & Tanah berpasir & 2 \\
& & Tanah lempung & 1.25 \\
& & Tanah liat & 1 \\
& &
\end{tabular}

Tabel 2. Nilai.infiltrasi minimum pada berbagai.kondisi.tanah

\begin{tabular}{|c|c|c|}
\hline Kelompok & Pengertian & $\begin{array}{l}\text { Infiltrasi minimum } \\
\qquad(\mathrm{mm} / \mathrm{jam})\end{array}$ \\
\hline A & $\begin{array}{l}\text { Potensi limpasan yang rendah. Tanah } \\
\text { mempunyai tingkat infiltrasi yang tinggi } \\
\text { meskipun ketika tergenang dan kedalaman } \\
\text { genangan yang tingi, pengeringan/penyerapan } \\
\text { baik unsur pasir dan batuan }\end{array}$ & $>0.45$ \\
\hline B & $\begin{array}{l}\text { Tanah yang mempunyai tingkat infiltrasi } \\
\text { biasa/medium ketika tergenang dan mempunyai } \\
\text { tingkat kedalaman genangan medium, } \\
\text { pengeringan dengan keadaan biasa didapat dari } \\
\text { moderately fine to moderately course }\end{array}$ & $0.30-0.15$ \\
\hline $\mathrm{C}$ & $\begin{array}{l}\text { Tanah mempunyai tingkat infiltrasi rendah jika } \\
\text { lapisan tanah untuk pengaliran air dengan } \\
\text { tingkat tekstur bias ke tekstur baik. Contoh: } \\
\text { lempung, pasir bernalau }\end{array}$ & $0.15-0.05$ \\
\hline $\mathrm{D}$ & 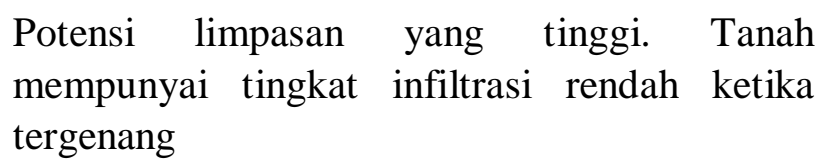 & $0.05-0.00$ \\
\hline
\end{tabular}




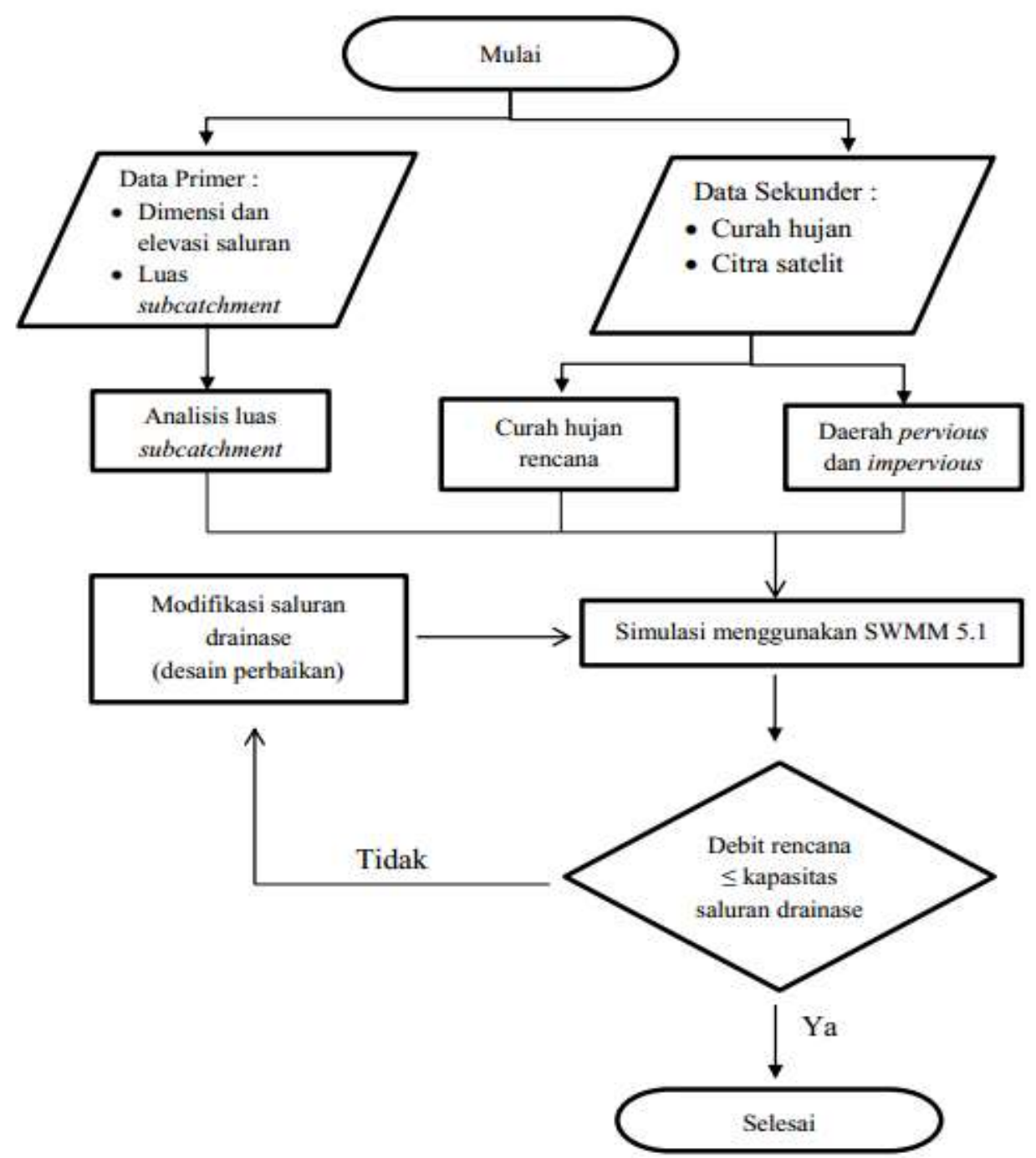

\section{Langkah Gambar 2. Tahapan penelitian} penggunaan SWMM adalah pembagian subcatchment pada area penelitian. Pembagian tersebut sesuai dengan daerah tangkapan air (DTA) yang ditentukan berdasarkan pada elevasi lahan dan pergerakan limpasan ketika terjadi hujan. Pembuatan model jaringan dilakukan berdasarkan sistem jaringan drainase yang ada di lapangan. Model jaringan ini terdiri dari subcatchment, node junction, conduit, outfall node, dan rain gage. Setelah model jaringan, selanjutnya dimasukkan semua nilai parameter yang dibutuhkan. Simulasi dapat dikatakan berhasil jika continuity error $<10 \%$. Dalam simulasi SWMM besarnya debit banjir dihitung drainase. Aliran permukaan atau limpasan permukaan terjadi ketika intensitas hujan yang jatuh di suatu daerah melebihi kapasitas infiltrasi. Visualisasi hasil yang ditampilkan berupa jaringan saluran drainase hasil output dari simulasi, profil aliran dari beberapa saluran utama, dan grafik aliran yang terjadi pada saluran.

\section{HASIL DAN PEMBAHASAN}

\section{Keadaan Umum Perumahan Tasmania}

Perumahan Tasmania terletak di kelurahan Tanahbaru, Kecamatan Bogor 
Utara, Kota Bogor, Jawa Barat. Luas Perumahan Tasmania yaitu \pm 12 ha dengan ketinggian berkisar 213-231 mdpl. Kondisi tata guna lahan pada lokasi penelitian didominasi oleh permukiman dan pengerasan jalan dengan aspal. Permasalahan yang terjadi di Perumahan Tasmania adalah kondisi saluran drainase yang tidak terawat dan dimensi saluran drainase di Perumahan Tasmania yang tidak teratur sehingga seringkali terjadi banjir saat curah hujan cukup besar. Faktor lain yang menjadi penyebab dari meluapnya saluran drainase adalah sedimentasi maupun sampah yang menghalangi laju air ketika terjadi hujan walaupun tidak dapat dianalisis menggunakan SWMM 5.1. Pembersihan secara berkala serta kesadaran dari masyarakat dirasa perlu untuk mengurangi potensi terjadi banjir yang diakibatkan sampah dan sedimentasi pada saluran drainase.

\section{Analisis Data Curah Hujan}

Analisis dilakukan dengan menggunakan data data curah hujan harian dari tahun 2007 hingga 2016 milik Stasiun Badan Meteorologi, Klimatologi, dan Geofisika (BMKG). Curah hujan rencana dihitung berdasarkan data curah hujan harian maksimum selama 10 tahun yang dapat dilihat pada Tabel 3.

Dalam analisis hidrologi
terdapat analisis frekuensi yang
digunakan untuk memperkirakan hujan
rancangan dengan kemungkinan
tertinggi pada periode tertentu. Hasil
analisis frekuensi berfungsi sebagai
dasar perhitungan untuk mengantisipasi
setiap kemungkinan yang akan terjadi.
Data hidrologi yang diperlukan dalam
perancangan drainase adalah data curah

hujan dari stasiun pencatat curah hujan disekitar atau terdekat lokasi studi (Widodo dan Ningrum 2015). Analisis frekuensi dapat dilakukan dengan metoda probability distribution antara lain Distribusi Normal, Distribusi Log Normal, Distribusi Log-Person III, dan Distribusi Gumbel (Triatmodjo 2010).

Tabel 3. Data curah hujan harian maksimum selama 10 tahun

\begin{tabular}{cccc}
\hline Tahun & $\begin{array}{c}\text { Curah } \\
\text { Hujan } \\
\text { Maksimum } \\
(\mathrm{mm})\end{array}$ & Tahun & $\begin{array}{c}\text { Curah } \\
\text { Hujan } \\
\text { Maksimum } \\
(\mathrm{mm})\end{array}$ \\
\hline 2007 & 155.5 & 2012 & 116 \\
2008 & 104.5 & 2013 & 97.4 \\
2009 & 115.1 & 2014 & 169.1 \\
2010 & 144.5 & 2015 & 155.8 \\
2011 & 97.6 & 2016 & 108.6 \\
\hline
\end{tabular}

Kala ulang yang digunakan untuk menghitung nilai hujan rencana yaitu 2 , 5, 10, 25, dan 50 tahun. Kala ulang (return period) adalah waktu perkiraan di mana hujan dengan suatu besaran tertentu akan disamai atau dilampaui. Berdasarkan data curah hujan tahun 2007-2016 yang didapatkan dari BMKG untuk wilayah Kota Bogor, peluang terjadinya banjir paling besar adalah saat bulan Januari dan April yang memiliki curah hujan harian diatas $100 \mathrm{~mm}$ terbanyak. Hasil analisis frekuensi curah hujan rencana dapat dilihat pada Tabel 4. 
Tabel 4. Hasil analisa curah hujan rencana ( $\mathrm{mm})$

\begin{tabular}{|c|c|c|c|c|}
\hline \multirow{2}{*}{ PUH (tahun) } & \multicolumn{4}{|c|}{ Curah Hujan Rencana (mm) } \\
\hline & Normal & Log Normal & Log Pearson III & Gumbel \\
\hline 2 & 126.41 & 123.90 & 122.49 & 122.76 \\
\hline 5 & 149.09 & 147.76 & 147.19 & 155.00 \\
\hline 10 & 160.98 & 162.03 & 163.10 & 176.35 \\
\hline 25 & 172.59 & 177.32 & 182.92 & 203.32 \\
\hline 50 & 181.78 & 190.42 & 199.24 & 223.33 \\
\hline $\begin{array}{l}\text { Hasil per } \\
\text { hujan rencana } \\
\text { memiliki nilai } \\
\text { harus diuji kese } \\
\text { masing-masing } \mathrm{j} \\
\text { dilakukan denga } \\
\text { terhadap syarat } \mathrm{b} \\
\text { tiap distribusi. P } \\
\text { dapat dilihat da } \\
\text { statistik data } \\
\text { yaitu nilai Cs } \\
\text { parameter distril } \\
\text { dilihat pada Tabe }\end{array}$ & $\begin{array}{l}\text { an nilai } \\
\text { setiap } \\
\text { erbeda se } \\
\text { nya denga } \\
\text { istribusi. } \\
\text { akukan ti } \\
\text { arameter s } \\
\text { an tipe dis } \\
\text { ameter-par } \\
\text { natan lap } \\
\text { k. Perban } \\
\text { robabilitas }\end{array}$ & $\begin{array}{l}\text { bahy } \\
\text { men } \\
\text { Pear } \\
\text { keco } \\
\text { keco } \\
\text { metc } \\
\text { digu } \\
\text { Nila } \\
\text { peng } \\
\text { Log } \\
\text { Kua }\end{array}$ & $\begin{array}{l}\text { Data pada Tabel } \\
\text { va jenis distribusi } \\
\text { enuhi syarat. Jeni } \\
\text { son III selanjutny } \\
\text { cokan dengan uji } \\
\text { cokan dimaksudka } \\
\text { mengetahui apa } \\
\text { de distribusi } \\
\text { nakan dapat diteri } \\
\text { distribusi yang } \\
\text { ujian Chi Kuadrat } \\
\text { Pearson III. Hasil } \\
\text { drat dapat dilihat pa }\end{array}$ & $\begin{array}{l}\text { nenunjukkan } \\
\text { pearson III } \\
\text { stribusi Log } \\
\text { ilakukan uji } \\
\text { Kuadrat. Uji } \\
\text { tuk } \\
\text { pemilihan } \\
\text { densi yang } \\
\text { atau ditolak. } \\
\text { nakan untuk } \\
\text { itu distribusi } \\
\text { ujian uji Chi } \\
\text { Tabel } 6 \text {. }\end{array}$ \\
\hline
\end{tabular}

Tabel 5. Perbandingan parameter distribusi probabilitas

\begin{tabular}{|c|c|c|c|c|}
\hline \multirow{2}{*}{ Jenis distribusi } & \multirow{2}{*}{ Cs } & \multirow{2}{*}{$\mathrm{Ck}$} & \multicolumn{2}{|c|}{ Syarat } \\
\hline & & & Cs & $\mathrm{Ck}$ \\
\hline Gumbel & 0.47 & 2.4787 & $\mathrm{Cs}=1.14$ & $\mathrm{Ck}=5.4$ \\
\hline Normal & 0.47 & 2.4787 & $\mathrm{Cs} \approx 0$ & $\mathrm{Ck} \approx 3$ \\
\hline Log normal & 0.47 & 2.4787 & $\mathrm{Cs}=0.43$ & $\mathrm{Ck}=3.33$ \\
\hline Log pearson III & 0.47 & 2.4787 & \multicolumn{2}{|c|}{ selain dari nilai di atas } \\
\hline
\end{tabular}

Tabel 6. Uji Chi Kuadrat distribusi Log Person III

\begin{tabular}{ccccccc}
\hline Kelas & Interval & Oi & Ei & Oi-Ei & $(\mathrm{Oi}-\mathrm{Ei})^{2}$ & $(\mathrm{Oi}-\mathrm{Ei})^{2} / \mathrm{Ei}$ \\
\hline 1 & $88.4375-106.3625$ & 3 & 2 & 1 & 1 & 0.5 \\
2 & $106.3625-124.2875$ & 3 & 2 & 1 & 1 & 0.5 \\
3 & $124.2875-142.2125$ & 0 & 2 & -2 & 4 & 2 \\
4 & $142.2125-160.1375$ & 3 & 2 & 1 & 1 & 0.5 \\
5 & $160.1375-178.0625$ & 1 & 2 & -1 & 1 & 0.5 \\
\hline \multicolumn{6}{r}{} \\
\hline
\end{tabular}

Data pada Tabel 6 menunjukkan nilai $\mathrm{x}^{\wedge} 2$ yang didapatkan sebesar 4 . Hal ini menunjukkan pengujian untuk distribusi Log Pearson III dapat diterima karena nilai $\mathrm{x}^{\wedge} 2$ perhitungan lebih kecil dari $\mathrm{Xcr}^{\wedge} 2$ pada tabel uji Chi Kuadrat yang nilainya 9.404. Nilai yang digunakan merujuk pada Tabel 4 periode ulang 5 tahun yaitu $147.19 \mathrm{~mm}$ nilai tersebut ditentukan berdasarkan 
Peraturan Menteri PU Nomor 12 Tahun 2014 untuk analisis saluran drainase pada daerah tangkapan air yang luasnya 10 sampai $100 \mathrm{Ha}$.

\section{Evaluasi Saluran Drainase dengan Model SWMM 5.1}

Pemodelan jaringan drainase di Perumahan Tasmania menggunakan software SWMM 5.1 dengan bangunan hidrolik yang digambarkan dalam pemodelan berupa subcatchment, junction node, outfall node, dan conduit berdasarkan data yang didapatkan dari observasi di lapangan. Jumlah junction node yang ada di Perumahan Tasmania berjumlah 113 node, 7 outfall node, 71 subcatchment, dan 111 conduit. Tidak ada debit luar yang masuk kedalam sistem drainase Perumahan Tasmania, karena dibatasi oleh sungai kecil di sebelah timur dan barat dapat dilihat pada Lampiran 2 dengan sungai ciluar sebagai outletnya. Curah hujan yang digunakan dalam simulasi sebesar 147,2 mm. Distribusi hujan per jam yang digunakan berdasarkan pada distribusi yang dikembangkan Tanimoto (1969) dalam Triatmodjo (2008) seperti ditunjukkan dalam Tabel 7.

Nilai distribusi hujan yang ditunjukkan pada Tabel 7 digunakan sebagai data hujan rencana dengan time series dan dimasukkan ke dalam pemodelan SWMM 5.1. Jam pertama memiliki nilai curah hujan dengan intensitas tertinggi yang merupakan jam puncak simulasi dan memiliki potensi yang besar untuk terjadinya limpasan. Intensitas curah hujan yang menjadi acuan dalam menentukan kondisi saluran adalah $38.27 \mathrm{~mm} / \mathrm{jam}$ dengan koefisien pengaliran sebesar 0.9 karena kondisi permukaan tanah merupakan jalan aspal. Modulus drainase pada Perumahan Tasmania sebesar 0.01 $\mathrm{m}^{3} /$ detik/ha. Subcatchment pada Perumahan Tasmania dibagi dengan bantuan citra satelit menggunakan software Google Earth yang diambil pada tanggal 1 Juli 2018 dan perkiraan arah aliran saat terjadi runoff. Luas area pada subcatchment didapatkan dari fitur Auto-Length pada SWMM 5.1 pada backdrop yang telah dilakukan geo reference sehingga memudahkan dalam pengukuran dan hasil yang cukup akurat. Simulasi dilakukan dengan asumsi saluran yang bermasalah dianggap normal. Hasil simulasi model jaringan drainase dan pola aliran Perumahan Tasmania pada jam puncak dapat dilihat pada Gambar 3.

Simulasi dilakukan setelah pemodelan jaringan drainase selesai digambarkan di SWMM 5.1 dengan menggunakan data yang didapatkan dari pengukuran langsung. Nilai continuity error dari hasil simulasi adalah $0.73 \%$ untuk Surface Runoff dan $0.01 \%$ untuk Flow Routing. Rossman (2015) menyatakan bahwa jika nilai continuity error yang merupakan penjumlahan dari Surface Runoff dengan Flow Routing mencapai $10 \%$ maka analisis diragukan, dengan demikian hasil simulasi pada penelitian ini dapat diterima.

Tabel 7. Distribusi curah hujan

\begin{tabular}{lrrrrrrrrr}
\hline waktu (jam) & 0 & 1 & 2 & 3 & 4 & 5 & 6 & 7 & 8 \\
\hline distribusi hujan & 0 & 26 & 24 & 17 & 13 & 7 & 5.5 & 4 & 3.5 \\
\hline CH rencana $(\mathrm{mm})$ & 0 & 38.27 & 35.33 & 25.02 & 19.14 & 10.30 & 8.10 & 5.89 & 5.15 \\
\hline
\end{tabular}

Hasil simulasi pada saluran drainase menggunakan
SWMM menunjukkan perbedaan kondisi kapasitas saluran yang ditampilkan 
dengan warna yang berbeda. Warna merah pada saluran $3,4,5,6,7,8,9$, $11,34,36,42,43,50,54,55,72,74$, 77, 79, dan 87 menunjukkan kapasitas saluran tidak dapat menampung aliran yang terjadi dan dapat dipastikan terjadi peluapan pada saat jam puncak hujan. Disamping itu, pada saluran 9, 12, 17, 32, 39, dan 111 mutlak dilakukan normalisasi (pembersihan penyumbatan) agar hasil analisis ini valid.
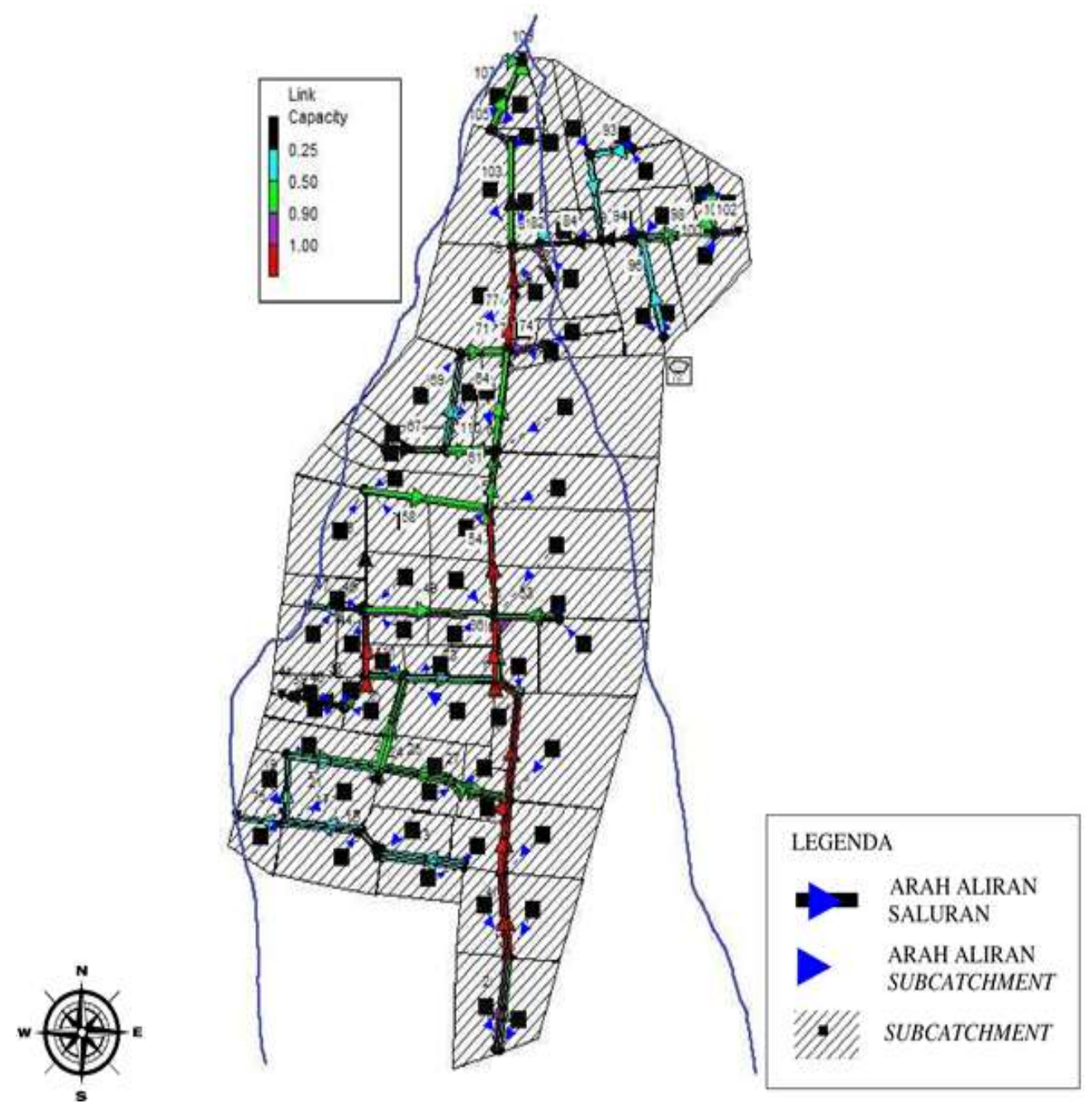

Gambar 3. Simulasi model jaringan drainase dan pola aliran

Warna ungu menunjukkan kondisi saluran yang juga memiliki potensi besar terjadi peluapan pada saat jam puncak hujan, seperti pada saluran 2, 48, 51, 86, 102, dan 105. Salah satu faktor yang mempengaruhi adalah besarnya limpasan yang terjadi dan rendahnya nilai infiltrasi pada subcatchment sehingga hanya sedikit air yang mampu diserap tanah dan sisanya mengalir sebagai runoff. Total infiltrasi paling besar terjadi pada subcatchment 8 dan 21 yang merupakan lahan kosong yaitu sebesar $4.87 \mathrm{~mm}$. Persentase daerah impervious pada subcatchment 8 dan 21 lebih sedikit sehingga memiliki nilai infiltrasi yang besar. Debit puncak tertinggi terjadi pada subcatchment 44 sebesar $0.08 \mathrm{~m}^{3} /$ detik. Subcatchment 44 menghasilkan total runoff terbanyak, 
yaitu sebesar 1.09 x 106 liter. Berikut grafik yang menunjukkan pergerakan debit limpasan yang terjadi terhadap yang hampir mencapai kapasitas maksimum, sehingga juga perlu dilakukan perbaikan untuk

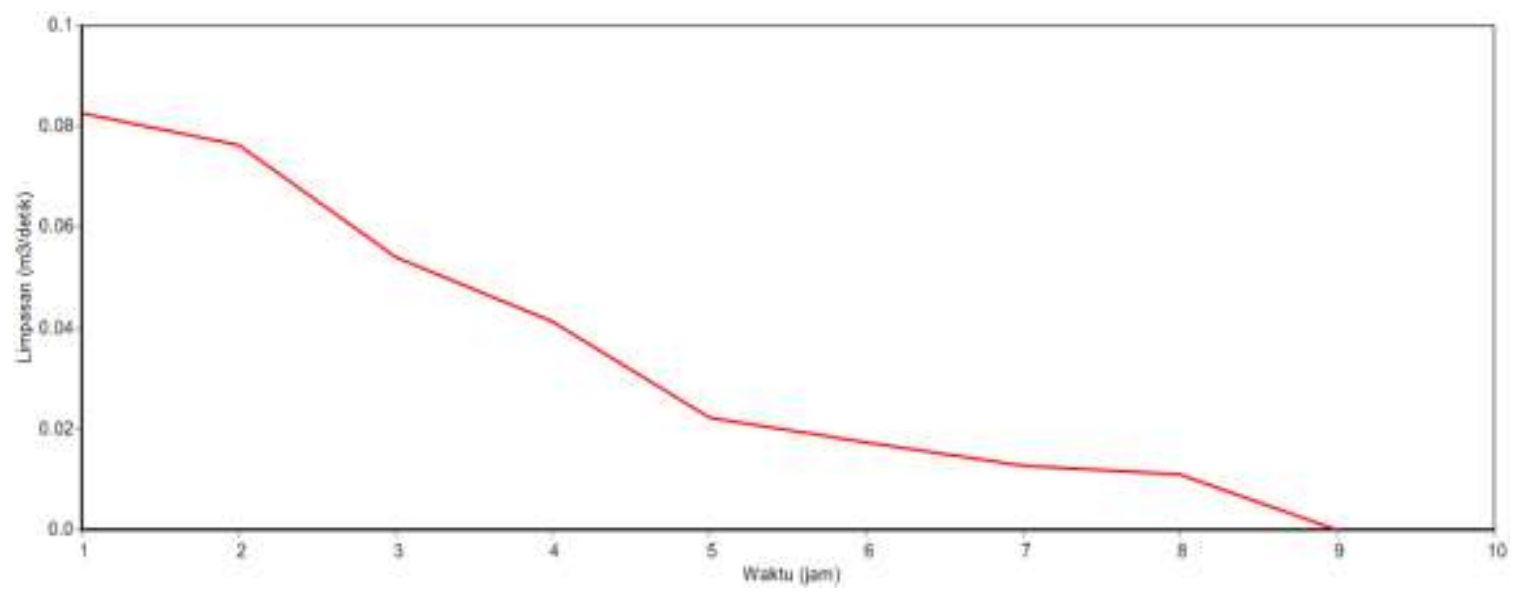

Gambar 4. Volume limpasan pada subcatchment 44

waktu pada subcatchment 44 dapat dilihat pada Gambar 4.

Runoff tertinggi terjadi pada jam pertama yang merupakan jam puncak dari distribusi curah hujan. Hasil tersebut menunjukkan bahwa potensi luapan atau banjir terbesar berada pada jam pertama. Saluran 50 merupakan saluran yang terjadi peluapan dengan perbandingan debit simulasi dan debit tampung maksimum terbesar yaitu 1.77 , hal tersebut disebabkan dimensi saluran yang tidak memadai untuk menampung limpasan yang terjadi. Node inlet pada saluran 50 adalah junction $\mathrm{J} 2 \mathrm{~L}$ dengan junction $\mathrm{J} 1 \mathrm{~L}$ sebagai node outletnya. Profil aliran pada saluran 50 saat hujan jam pertama dapat dilihat pada Gambar 5.

Gambar 5 menunjukkan kondisi saluran 50 yang sudah terisi penuh sehingga tidak dapat lagi menampung besarnya debit hujan yang terjadi dan menimbulkan runoff yang berpotensi menyebabkan banjir. Hal tersebut juga terjadi pada seluruh saluran yang berwarna merah pada saat simulasi jam pertama seperti pada Gambar 3. Saluran yang berwarna ungu saat simulasi jam pertama menunjukkan kondisi saluran mengantisipasi luapan.

Berdasarkan simulasi yang telah dilakukan, diketahui lokasi saluran yang perlu dilakukan perbaikan. Perbaikan dilakukan dengan mengubah dimensi saluran drainase yang mencapai kapasitas maksimum pada jam pertama simulasi. Perencanaan ulang dilakukan dengan mencoba merencanakan lebar dan tinggi saluran sehingga didapatkan kapasitas tampungan yang cukup optimal (Suroso 2014). Perencanaan ulang saluran drainase dilakukan dengan metode trial and error pada aplikasi $\quad$ SWMM 5.1 hingga mendapatkan dimensi lebar dan tinggi saluran tanpa banyak mengubah kondisi awal agar biaya yang dikeluarkan untuk renovasi saluran tidak terlalu besar. Perlu diperhatikan besarnya dimensi lebar maupun kedalaman yang ditambahkan, dengan menambah kedalaman saluran maka tinggi muka air perlu diperhatikan agar tidak terjadi aliran balik (backwater) terhadap saluran yang diperbaiki, sedangkan dengan menambah lebar saluran maka lebar jalan akan berkurang sehingga sebaik mungkin dihindari. Perbaikan dimensi saluran yang dilakukan 


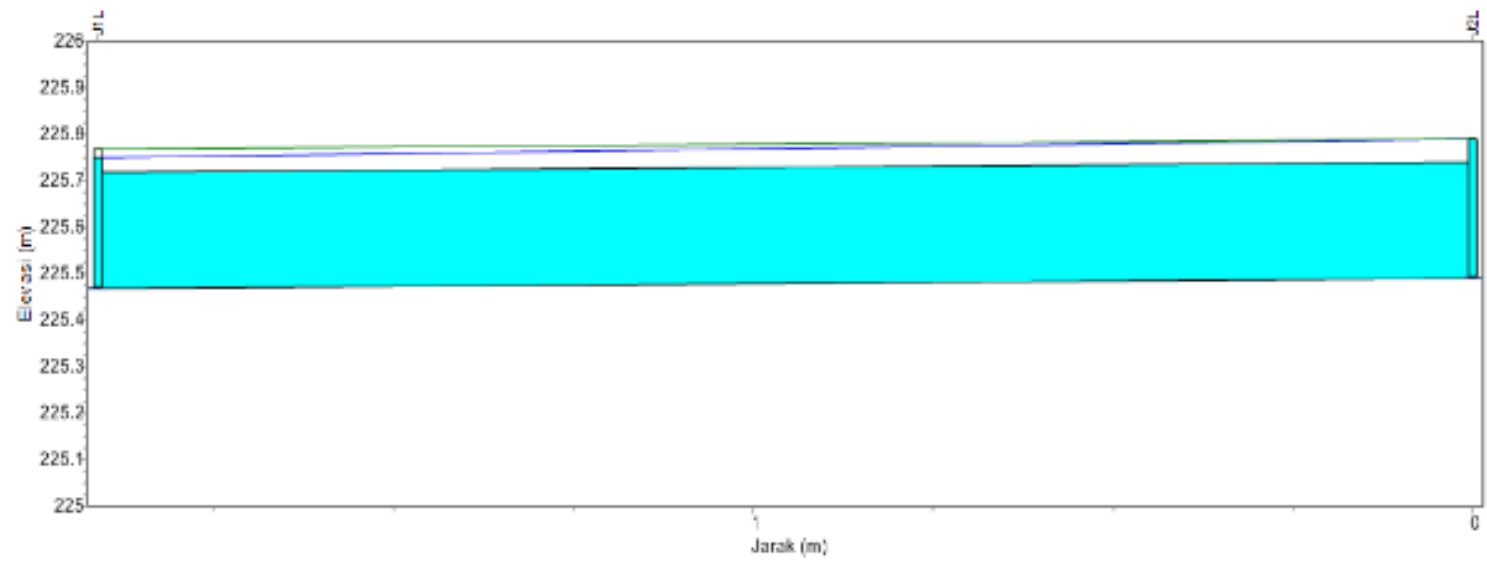

Gambar 5. Profil aliran saluran 50 pada jam pertama

berdampak kepada saluran lain karena dapat mengubah debit saluran di sekitarnya. Ilustrasi perbandingan tinggi muka air sebelum dan sesudah dilakukan perbaikan dapat dilihat pada Gambar 6. Terdapat 11 saluran yang juga perlu dilakukan perbaikan selain saluran yang berwarna merah dan ungu, diantaranya saluran $10,32,35,59,60$, 61, 62, 63, 64, 71, dan 80. Dimensi saluran sebelum dan sesudah dilakukan perancangan ulang dapat dilihat pada Tabel 8.

Dimensi saluran 50 semula memiliki lebar sebesar $0.25 \mathrm{~m}$ dan kedalaman saluran $0.25 \mathrm{~m}$, setelah dilakukan evaluasi dimensi saluran menjadi $0.3 \mathrm{~m}$ lebar dan kedalaman saluran sebesar $0.6 \mathrm{~m}$. Data lebar dan tinggi saluran yang telah dilakukan perbaikan selanjutnya digunakan dalam SWMM 5.1 untuk dilakukan simulasi ulang. Simulasi ulang dilakukan untuk mengetahui kondisi model jaringan drainase setelah perbaikan dilakukan. Perbaikan saluran drainase dianggap berhasil apabila tidak ada saluran yang berwarna merah atau ungu pada jam pertama. Hasil simulasi jaringan drainase Perumahan Tasmania setelah dilakukan perbaikan dapat dilihat pada Gambar 7. Berdasarkan hasil simulasi menggunakan dimensi saluran yang telah diperbaiki, tidak ada saluran yang meluap pada jam pertama dilihat dari tidak ada warna merah maupun ungu pada Gambar 7. Profil aliran pada saluran 50 yang meluap pada jam pertama sudah menjadi normal dan dapat dilihat pada Gambar 8.

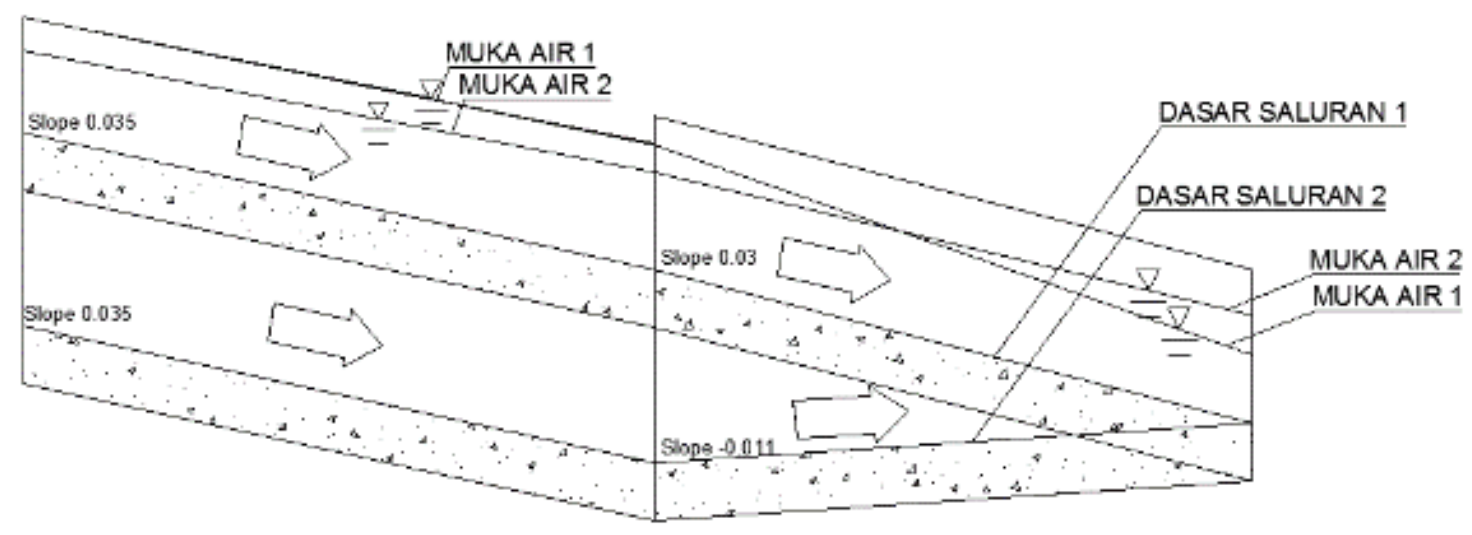

Gambar 6. Ilustrasi muka air setelah perbaikan (diperdalam) 


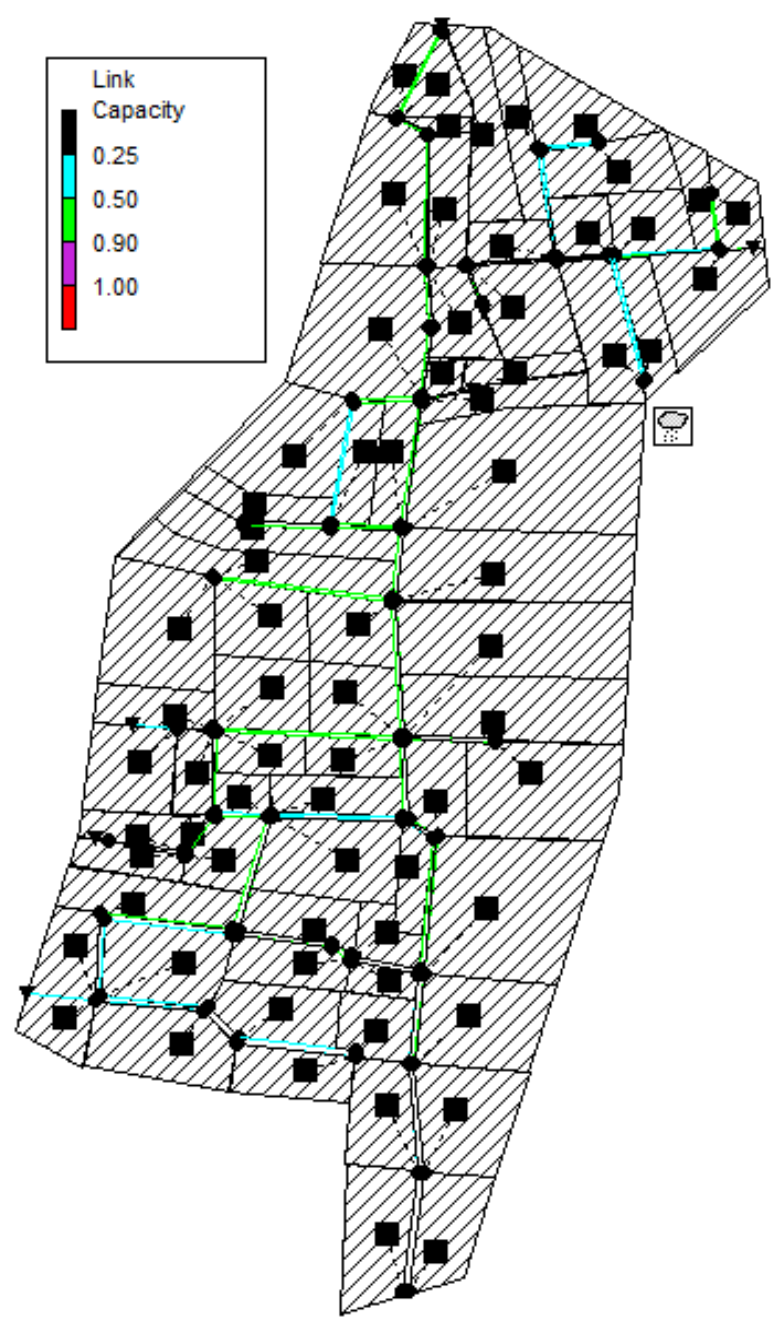

Gambar 7. Simulasi model jaringan drainase setelah perbaikan

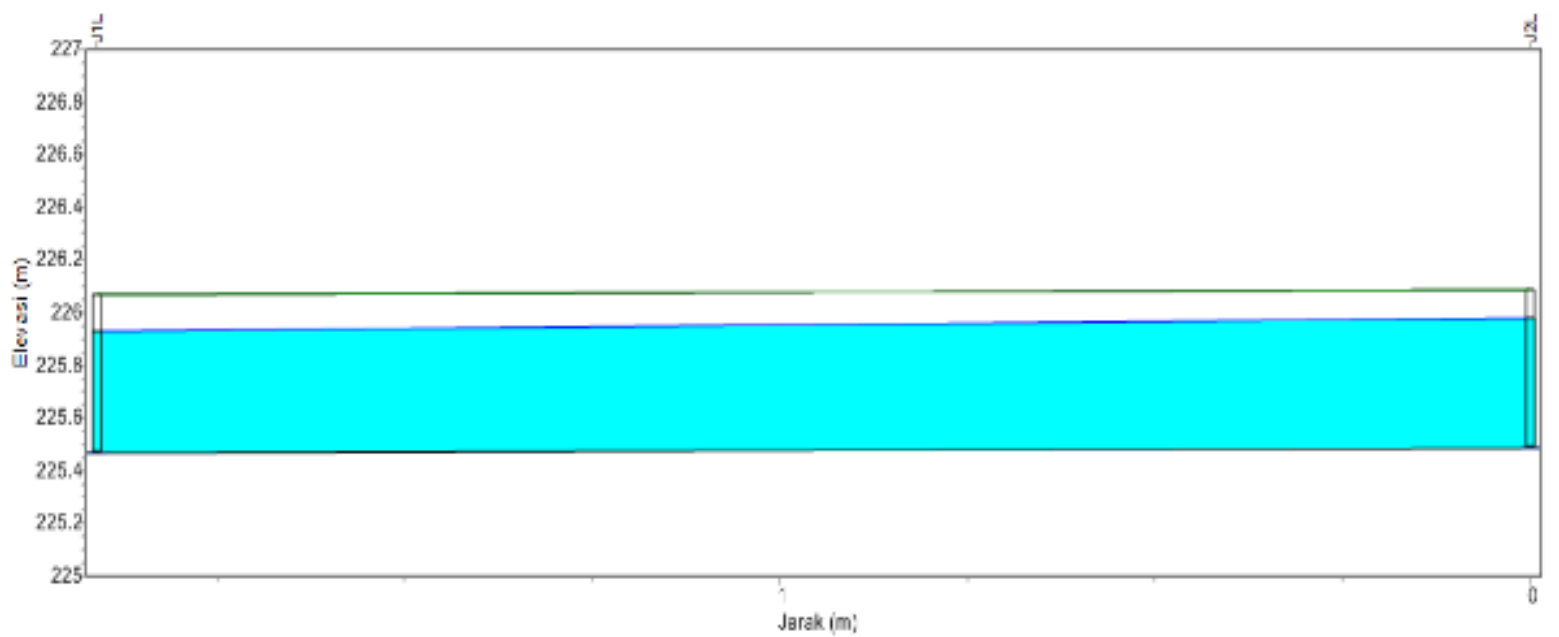

Gambar 8. Profil aliran saluran 50 pada jam pertama setelah perbaikan 
Tabel 8. Dimensi saluran sebelum dan sesudah perbaikan

\begin{tabular}{|c|c|c|c|c|c|}
\hline \multicolumn{3}{|c|}{$\begin{array}{c}\text { Dimensi sebelum } \\
\text { perbaikan }\end{array}$} & \multicolumn{3}{|c|}{ Dimensi setelah perbaikan } \\
\hline Saluran & $\begin{array}{c}\text { Lebar } \\
(\mathrm{m})\end{array}$ & $\begin{array}{l}\text { Tinggi } \\
(\mathrm{m})\end{array}$ & Saluran & $\begin{array}{l}\text { Lebar } \\
(\mathrm{m})\end{array}$ & $\begin{array}{l}\text { Tinggi } \\
(\mathrm{m})\end{array}$ \\
\hline 2 & 0.20 & 0.15 & 2 & 0.20 & 0.40 \\
\hline 3 & 0.20 & 0.15 & 3 & 0.20 & 0.40 \\
\hline 4 & 0.20 & 0.15 & 4 & 0.20 & 0.40 \\
\hline 5 & 0.20 & 0.15 & 5 & 0.20 & 0.40 \\
\hline 6 & 0.20 & 0.15 & 6 & 0.20 & 0.40 \\
\hline 7 & 0.20 & 0.15 & 7 & 0.20 & 0.40 \\
\hline 8 & 0.20 & 0.15 & 8 & 0.30 & 0.60 \\
\hline 9 & 0.20 & 0.15 & 9 & 0.20 & 0.40 \\
\hline 10 & 0.20 & 0.15 & 10 & 0.30 & 0.80 \\
\hline 11 & 0.20 & 0.15 & 11 & 0.30 & 0.60 \\
\hline 32 & 0.30 & 0.40 & 32 & 0.30 & 0.60 \\
\hline 34 & 0.25 & 0.15 & 34 & 0.25 & 0.60 \\
\hline 35 & 0.25 & 0.15 & 35 & 0.30 & 0.60 \\
\hline 36 & 0.25 & 0.15 & 36 & 0.25 & 0.60 \\
\hline 42 & 0.25 & 0.20 & 42 & 0.30 & 0.40 \\
\hline 43 & 0.25 & 0.20 & 43 & 0.30 & 0.40 \\
\hline 48 & 0.25 & 0.30 & 48 & 0.25 & 0.60 \\
\hline 50 & 0.25 & 0.25 & 50 & 0.30 & 0.60 \\
\hline 51 & 0.25 & 0.25 & 51 & 0.25 & 0.60 \\
\hline 54 & 0.25 & 0.25 & 54 & 0.25 & 0.60 \\
\hline 55 & 0.25 & 0.25 & 55 & 0.25 & 0.60 \\
\hline 59 & 0.27 & 0.50 & 59 & 0.30 & 0.60 \\
\hline 60 & 0.27 & 0.50 & 60 & 0.30 & 0.60 \\
\hline 61 & 0.27 & 0.50 & 61 & 0.30 & 0.60 \\
\hline 62 & 0.27 & 0.50 & 62 & 0.30 & 0.60 \\
\hline 63 & 0.27 & 0.50 & 63 & 0.30 & 0.60 \\
\hline 64 & 0.27 & 0.50 & 64 & 0.30 & 0.60 \\
\hline 71 & 0.25 & 0.25 & 71 & 0.25 & 0.60 \\
\hline 72 & 0.27 & 0.50 & 72 & 0.40 & 0.80 \\
\hline 74 & 0.30 & 0.20 & 74 & 0.40 & 0.80 \\
\hline 77 & 0.27 & 0.50 & 77 & 0.40 & 0.80 \\
\hline 79 & 0.20 & 0.25 & 79 & 0.40 & 0.80 \\
\hline 80 & 0.25 & 0.30 & 80 & 0.30 & 0.80 \\
\hline 86 & 0.20 & 0.20 & 86 & 0.20 & 0.40 \\
\hline 87 & 0.20 & 0.20 & 87 & 0.20 & 0.40 \\
\hline 102 & 0.20 & 0.30 & 102 & 0.20 & 0.40 \\
\hline 105 & 0.25 & 0.30 & 105 & 0.30 & 0.80 \\
\hline
\end{tabular}




\section{SIMPULAN DAN SARAN}

\section{Simpulan}

Simulasi telah dilakukan menggunakan EPA SWMM 5.1 dengan curah hujan rencana sebesar $147.2 \mathrm{~mm}$ dan intensitas hujan jam puncak sebesar $38.27 \mathrm{~mm} / \mathrm{jam}$. Hasil simulasi menunjukkan terdapat terdapat 37 saluran yang perlu dilakukan perbaikan. Sebanyak 20 saluran terjadi limpasan, 6 saluran berpotensi besar terjadi limpasan, dan 11 saluran yang juga perlu dilakukan perbaikan karena pengaruh perubahan dimensi saluran di sekitarnya. Rancangan saluran drainase perbaikan memiliki dimensi lebar dan kedalaman yang lebih besar dengan kisaran 0.2 - $0.4 \mathrm{~m}$ lebar dan $0.4-0.8 \mathrm{~m}$ dalam. Tidak ditemukan saluran bermasalah setelah dilakukan simulasi ulang menggunakan dimensi saluran perbaikan, sehingga dimensi dimensi saluran setelah perbaikan dianggap aman.

\section{Saran}

1. Analisis curah hujan dapat menggunakan metode Polygon Thiessen apabila data curah hujan dari tiga stasiun cuaca terdekat tersedia.

2. Perlu dilakukan pengujian terhadap persentase zero impervious yang merupakan area impervious tanpa depression storage.

3. Dilakukan normalisasi terhadap saluran 9, 12, 17, 32, 39, dan 111 agar hasil simulasi dan perhitungan dapat diterapkan.

4. Perlu diperhatikan slope saluran setelah dilakukan perbaikan agar tidak terjadi arus balik.

\section{DAFTAR PUSTAKA}

Ardian RB, Zakaria A, Susilo GE. 2016. Study System Drainase di
Fakultas Teknik Universitas Lampung. Jurnal Rekayasa Sipil dan Desain. 4:503-512.

Babbit HE. 1969. Sewage and Sewerage Treatment Plant. New York (US) : McGraw Hill.

[BPS] Badan Pusat Statistik. 2017. Penduduk Kota Bogor Menurut Jenis Kelamin dan Kecamatan [diunduh 3 Januari 2018] Tersedia pada:

https://bogorkota.bps.go.id/dynam ictable/2015/12/28/40/penduduk-

kota-bogor-menurut-jenis-

kelamin-dan-kecamatan.html.

Isfandari DT, Reini SI. 2014. Analisis

Sistem Drainase di Kawasan

Pemukiman pada Sub DAS Aur

Palembang (Studi Kasus:

Pemukiman 9/10 Ulu). Jurnal

Teknik Sipil dan

Lingkungan.2:131-136.

Kodoatie RJ. 2005. Pengantar Manajemen Infrastruktur. Yogyakarta (ID): Pustaka Pelajar.

Krisnayanti DS, Hunggurami E, Wea KND. 2017. Perencanaan Drainase Kota Seba. Jurnal Teknik Sipil. 6:89-102.

Rossman L. 2015. Storm Water Management Model User's Manual Version 5.0. Cincinnati. Washington (US): EPA United Stated Evironmental Agency.

Sudarmanto B. 2010. Sistem Drainase Perkotaan yang Berwawasan Lingkungan. Semarang (ID): Fakultas Teknik Universitas Wahid Hasyim.

Suroso, Suharyanto A, Anwar MR, Pudyono, Wicaksono DH. 2014. Evaluasi dan Perencanaan Ulang Saluran Drainase pada Kawasan Perumahan Sawojajar Kecamatan Kedungkandang Kota Malang. Jurnal Rekayasa Sipil. 8(3): 207213. 
Tamimi R, Wahyuni S, Hidayah E. 2016. Kajian Evaluasi Sistem Drainase Jalan Srikoyo Kecamatan Patrang Kabupaten Jember. Jurnal Rekayasa Sipil dan Lingkungan. 1:18-31.

Triatmodjo B. 2008. Hidrologi Terapan.Yogyakarta(ID): Beta Offset.

Triatmodjo B. 2010. Hidraulika II. Yogyakarta (ID): Beta Offset.

Widodo E, Ningrum D. 2015. Evaluasi Sistem Jaringan Drainase Permukiman Soekarno Hatta Kota Malang dan Penanganannya. Jurnal Ilmu-ilmu Teknik. 1(3): 1 9. 
JSIL | Luthfi Kartika dkk. : Analisis Kapasitas Saluran Drainase 